\title{
Rheological characterization of $\kappa$-carrageenan/galactomannan and xanthan/galactomannan gels: Comparison of galactomannans from non-traditional sources with conventional galactomannans
}

\author{
A.C. Pinheiro ${ }^{a}$, A.I. Bourbon a , C. Rocha ${ }^{\text {b }}$, C. Ribeiro ${ }^{\mathrm{a}, \mathrm{c}}$, J.M. Maia ${ }^{\mathrm{d}, \mathrm{e}}$, M.P. Gonçalves ${ }^{\mathrm{b}}$, \\ J.A. Teixeira ${ }^{a}$, A.A. Vicente ${ }^{a, *}$ \\ a IBB - Institute for Biotechnology and Bioengineering, Centre of Biological Engineering, University of Minho, Campus de Gualtar, 4710-057 Braga, Portugal \\ ${ }^{\mathrm{b}}$ REQUIMTE - Department of Chemical Engineering, Faculty of Engineering, University of Porto, Rua Dr. Roberto Frias, $4200-465$ Porto, Portugal \\ ${ }^{c}$ Research and Development Department, Frulact, S.A., Rua do Outeiro, 589, Gemunde, 4475-150 Maia, Portugal \\ d IPC - Institute for Polymers and Composites, Department of Polymer Engineering, University of Minho, Campus de Azurém, 4800-058 Guimarães, Portugal \\ e Case Western Reserve University, Department of Macromolecular Science and Engineering, 2100 Adelbert Rd., Cleveland, OH 44106, United States
}

\section{A R T I C L E I N F O}

\section{Article history:}

Received 1 June 2010

Received in revised form 23 July 2010

Accepted 28 July 2010

Available online 6 August 2010

\section{Keywords:}

Gleditsia triacanthos

Sophora japonica

Guar gum

Locust bean gum

Synergistic interactions

Rheological characterization

\begin{abstract}
A B S T R A C T
The synergistic interactions of two non-conventional galactomannans (Gleditsia triacanthos galactomannan (mannose/galactose ratio $[M / G]=2.82$ ) and Sophora japonica galactomannan $(M / G=5.75)$ ) with $\kappa$-carrageenan and xanthan were quantified and compared with those of two traditional galactomannans (guar gum $-\mathrm{M} / \mathrm{G}=1.8$ and locust bean gum $-\mathrm{M} / \mathrm{G}=3.5$ ) with the same polysaccharides. The main objective was to evaluate the effectiveness of the former as alternative galactomannan sources. The rheological behavior of the resulting binary systems was characterized using dynamic oscillatory measurements.

For $\kappa$-carrageenan/galactomannans mixtures, the synergistic interactions were stronger for mixtures of $60 / 40(\% \mathrm{w} / \mathrm{w}) \kappa$-carrageenan/locust bean gum, 60/40 (\% w/w) $\kappa$-carrageenan/S. japonica galactomannan, $80 / 20(\% \mathrm{w} / \mathrm{w}) \mathrm{\kappa}$-carrageenan/guar gum and $60 / 40(\% \mathrm{w} / \mathrm{w}) \mathrm{\kappa}$-carrageenan/G. triacanthos galactomannan. For all xanthan/galactomannans systems, the maximum synergy was observed for a ratio of $20 / 80$ (\% $\mathrm{w} / \mathrm{w})$.

The synergistic effects of $\kappa$-carrageenan/galactomannans and xanthan/galactomannans systems seem to depend not only on the $\mathrm{M} / \mathrm{G}$ ratio but also on the fine structure of the galactomannans, since the strongest synergy was observed for locust bean gum followed by S. japonica galactomannan, guar gum and G. triacanthos galactomannan.
\end{abstract}

(c) 2010 Elsevier Ltd. All rights reserved.

\section{Introduction}

Galactomannans are neutral polysaccharides obtained from the seed endosperm of some Leguminosae, where they serve as energy reserve. They are composed of a linear mannose $(\mathrm{M})$ backbone bearing side chains with a single galactose $(G)$ unit. Depending on the botanical origin, they differ in the mannose/galactose $(M / G)$ ratio, molecular weight and in the distribution of the galactose units. Galactomannans find a wide range of food applications due to their ability to form very viscous solutions at low concentrations. Two galactomannans of major importance are guar gum (GG) and locust bean gum (LBG), which have M/G ratios of 1.8 and 3.5, respectively (Dakia, Blecker, Roberta, Watheleta, \& Paquota, 2008; Dea \& Morrison, 1975; Fox, 1992).

\footnotetext{
* Corresponding author. Tel.: +351253 604419; fax: +351253678986.

E-mail address: avicente@deb.uminho.pt (A.A. Vicente).
}

Galactomannans can synergistically interact with other biopolymers such as $\kappa$-carrageenan and xanthan, resulting in improved product quality and reduced production costs (Dea et al., 1977). Synergistic polysaccharide-polysaccharide interactions are attractive in the food industry because they offer the potential to create new textures and to manipulate the rheology of the products (Sworn, 2000, chap. 6). Many mixed systems formed by galactomannans and $\kappa$-carrageenan or xanthan already find extensive applications in the food industry.

$\kappa$-Carrageenan is a fraction of the sulphated polysaccharide family extracted from certain red seaweeds and is composed of alternating disaccharides of (1-3) linked $\alpha$-D-galactose-4-sulphate and (1-4) linked 3,6-anhydro- $\alpha$-D-galactose monomers. The association between $\kappa$-carrageenan and galactomannans is believed to occur via unsubstituted regions of the mannan backbone, which are assumed to bind the carrageenan helix (Dea, McKinnon, \& Rees, 1972; Miles, Morris, \& Carroll, 1984). The synergistic effects observed with $\kappa$-carrageenan/galactomannan systems have been 
Table 1

Experimental design of the different mixtures evaluated.

\begin{tabular}{|c|c|c|c|}
\hline & Galactomannans ${ }^{\mathrm{a}}(\% \mathrm{w} / \mathrm{w})$ & к-Carrageenan (\% w/w) & Xanthan $(\% \mathrm{w} / \mathrm{w})$ \\
\hline \multirow[t]{5}{*}{ к-Carrageenan/galactomannan } & 0 & 100 & - \\
\hline & 20 & 80 & - \\
\hline & 40 & 60 & - \\
\hline & 60 & 40 & - \\
\hline & 80 & 20 & - \\
\hline Xanthan/galactomannan & 0 & - & 100 \\
\hline \multirow{4}{*}{ systems } & 20 & - & 80 \\
\hline & 40 & - & 60 \\
\hline & 60 & - & 40 \\
\hline & 80 & - & 20 \\
\hline
\end{tabular}

a Guar gum, locust bean gum, Gleditsia triacanthos galactomannan or Sophora japonica galactomannan.

found to be dependent on the M/G ratio (Dea \& Morrison, 1975; Dea et al., 1972; Fernandes, Gonçalves, \& Doublier, 1991).

Xanthan is an extracellular polysaccharide secreted by Xanthomonas campestris composed by pentasaccharide repeating units, with a $\beta-1,4$ linked cellulosic backbone, attached with a charged trisaccharides side chain docked on alternated glucose residue. Different models have been proposed to explain the intermolecular binding mechanism between xanthan and galactomannans, however considerable controversy still exists. The original model proposed that the intermolecular binding occurs between the ordered (helix) xanthan and unsubstituted or poorly substituted regions of the galactomannan backbone and that the synergistic interaction is strongly dependent on the galactose content (Dea et al., 1977; Morris, 1977).

The existing information about binary aqueous mixtures with non-traditional galactomannans is scarce. The galactomannan of Gleditsia triacanthos (Leguminosae) exhibits an M/G ratio of 2.82 and the galactomannan of Sophora japonica (also a Leguminosae) exhibits an unusually high M/G ratio (5.75) (Cerqueira et al., 2009). In a previous work (Bourbon et al., 2009), the rheological behavior of these galactomannans was evaluated and it was concluded that they can be used as efficient thickening agents, when compared with locust bean gum and guar gum. However, it is not known if they display synergistic effects with other polysaccharides, such as $\mathrm{\kappa}$-carrageenan or xanthan gum, nor which is the mixture ratio that corresponds to the "synergistic peak".

The aim of the present work was thus to investigate the rheological properties of $\kappa$-carrageenan/galactomannan and xanthan/galactomannan mixtures for different mixture ratios and to evaluate the effects of polymer concentration and temperature in the interaction strength. These synergistic interactions and the resulting rheological behavior of the mixtures may provide different properties to food products.

\section{Materials and methods}

\subsection{Materials}

The pods of G. triacanthos and S. japonica were collected in the Botanical Garden in Porto, Portugal, during April 2006 and Febru- ary 2008, respectively. The seeds were manually separated and kept in a cool, dry place until further use. Guar gum (Viscogum) and Xanthan gum were provided by Cargill (USA) and locust bean gum (Genu gum type RL-200V) and $\kappa$-carrageenan (WR-78) were provided by CP Kelco (USA). These polysaccharides were used as received.

\subsection{Methods}

\subsubsection{Polysaccharide extraction and purification}

The polysaccharide extraction of G. triacanthos and S. japonica seeds was performed according to Cerqueira et al. (2009). Briefly, the extraction of galactomannans from G. triacanthos seeds was performed with ethanol and distilled water. In this process, the seeds were mechanically broken, the endosperm was separated from the germ and the hull and was suspended in ethanol (purity 99.8\%, Riedel-de Haën, Germany) to inactivate the enzymes and to eliminate low-molecular-weight compounds (Egorov, Mestechkina, \& Shcherbukhin, 2003, 2004). Following this step, distilled water was added and the suspension was mixed in a blender.

The extraction procedure of galactomannan from the seeds of $S$. japonica required an acidic pre-treatment in order to effectively separate the hull from the endosperm. The seeds were peeled using sulphuric acid (purity 98\%, Fluka, Germany) (1:1) in a water bath at $100^{\circ} \mathrm{C}$ for $1.5 \mathrm{~h}$. After the separated endosperm had been treated with ethanol, water was added to it and the mixture was heated at $80^{\circ} \mathrm{C}$.

The purification processes of both galactomannans included a filtration through a nylon net followed by a centrifugation step at $3800 \times g$ (Sigma $4 \mathrm{~K}$, B.Braun, Germany) during $20 \mathrm{~min}$ at $20^{\circ} \mathrm{C}$. The precipitation of the galactomannan was achieved by adding the supernatant to ethanol (purity 99.8\%, Riedel-de Haën, Germany) at a ratio of $1: 2$. The precipitated galactomannan was lyophilized and kept in a dry place until further use (Cerqueira et al., 2009).

\subsubsection{Analysis of polysaccharide samples}

Moisture content was determined according to AOAC standards (Ranganna, 1977), protein content was assessed using Bradford's method (Bradford, 1976) and ash content was evaluated by heating the sample in a muffle furnace at $500^{\circ} \mathrm{C}$ for $8 \mathrm{~h}$ followed by cooling

Table 2

Composition of the polysaccharide samples ( $\pm 95 \%$ confidence interval).

\begin{tabular}{|c|c|c|c|c|c|}
\hline Sample & Moisture (\% w/w) & $\operatorname{Ash}(\% \mathrm{w} / \mathrm{w})$ & Protein $(\% \mathrm{w} / \mathrm{w})$ & Sodium (\% w/w) & Potassium (\% w/w) \\
\hline к-Carrageenan & $11.57 \pm 0.02$ & $23.94 \pm 0.01$ & n.d. ${ }^{a}$ & $0.54 \pm 0.01$ & $9.34 \pm 0.23$ \\
\hline Xanthan & $14.42 \pm 0.01$ & $5.82 \pm 0.01$ & $1.69 \pm 0.01$ & $4.03 \pm 0.08$ & $0.53 \pm 0.01$ \\
\hline S. japonica galactomannan & $13.39 \pm 0.02$ & $0.32 \pm 0.02$ & $0.06 \pm 0.02$ & - & - \\
\hline LBG & $11.38 \pm 0.01$ & $0.16 \pm 0.01$ & $0.01 \pm 0.002$ & - & - \\
\hline G. triacanthos galactomannans & $10.17 \pm 0.01$ & $0.08 \pm 0.01$ & $0.34 \pm 0.01$ & - & - \\
\hline GG & $11.70 \pm 0.03$ & $0.72 \pm 0.01$ & $0.01 \pm 0.008$ & - & - \\
\hline
\end{tabular}

a n.d., not detectable. 

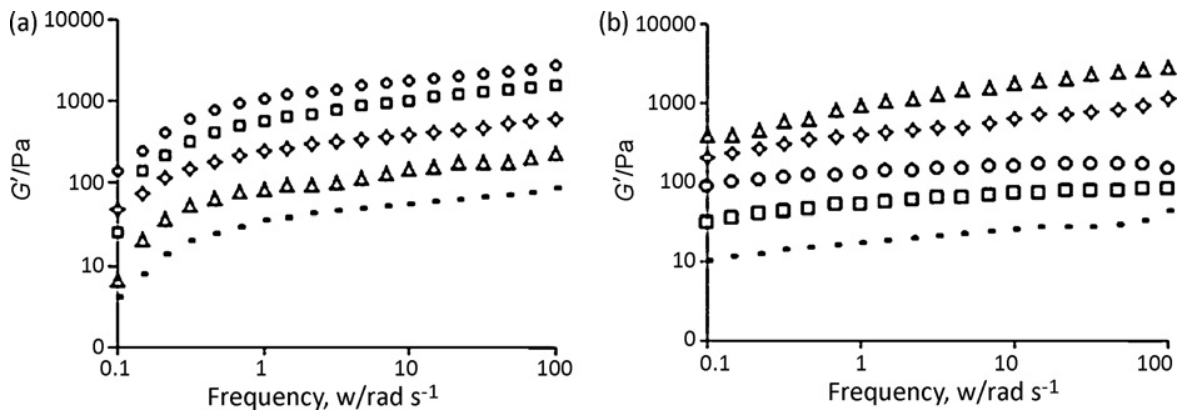

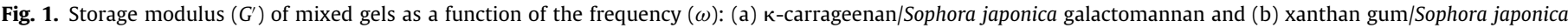
galactomannan at different ratios, at $25^{\circ} \mathrm{C}$. Total polymer concentration: $1.0 \%$; 100/0 (-), 20/80 ( $\left.\triangle\right), 40 / 60(\diamond), 60 / 40(\bigcirc), 80 / 20(\square)$.

and weighing (Ranganna, 1977). The determination of the sodium and potassium content in $\mathrm{\kappa}$-carrageenan and xanthan samples were performed by Neotrom SPA-Italy (UNI EN ISO 9001 Certified Laboratory). Three replicates were obtained for each sample.

\subsubsection{Preparation of polysaccharide solutions}

The required quantity of powdered polysaccharides was added to the appropriate amount of distilled water. The polysaccharides dispersions were stirred at room temperature under moderate agitation for $1 \mathrm{~h}$ and, with the exception of guar gum, further subjected to a stirring period $(30 \mathrm{~min})$ at a higher temperature $\left(80^{\circ} \mathrm{C}\right)$ in order to ensure their complete solubilisation. The solutions were centrifuged for $1 \mathrm{~h}$ at $20,000 \times \mathrm{g}$ and the supernatants were recovered. The final polymer concentrations of each polysaccharide solution were determined as total solids dried at $105^{\circ} \mathrm{C}$ until constant weight.

Mixtures ( $1 \% \mathrm{w} / \mathrm{w}$ total polysaccharide) were prepared by adding the required volume of each polymer solution to give different polymer ratios (see Table 1 ).

\subsubsection{Rheological measurements}

All rheological determinations were performed in triplicate for each mixture.

Before performing the rheological tests, the linear viscoelastic region was determined and the appropriate strain was selected, by means of strain sweeps conducted at two constant frequency values $\left(0.6279 \mathrm{rad} \mathrm{s}^{-1}\right.$ and $\left.6.279 \mathrm{rad} \mathrm{s}^{-1}\right)$ and variable strain ranging from $0.01 \%$ to $10 \%$. This type of test determines the maximum deformation that a system can withstand without structural failure.

2.2.4.1. Mechanical spectra. A time sweep step of $90 \mathrm{~min}$ at $6.279 \mathrm{rad} \mathrm{s}^{-1}$ was performed with an AR-G2 rheometer (TA Instruments, DE, USA), using parallel plates ( $40 \mathrm{~mm}$ diameter and $1 \mathrm{~mm}$ gap) before the frequency sweep measurements. Frequency sweeps were performed in the $0.1-100 \mathrm{rad} \mathrm{s}^{-1}$ range at $25^{\circ} \mathrm{C}$ and the strain was fixed at $5 \%$.

2.2.4.2. Cooling-heating cycles. Temperature sweeps were performed with controlled stress rheometer AR-G2 (TA Instruments, DE, USA) equipped with a Peltier system in the bottom plate for accurate temperature control using a parallel plate geometry (40 mm diameter, gap $1 \mathrm{~mm}$ ). Each sample was previously heated to $70^{\circ} \mathrm{C}$, equilibrated for $5 \mathrm{~min}$ and then cooled from $70^{\circ} \mathrm{C}$ to $25^{\circ} \mathrm{C}$ (in the case of systems with xanthan) or $20^{\circ} \mathrm{C}$ (for systems with $\kappa$-carrageenan). A time sweep of $90 \mathrm{~min}$ was then performed and the system was heated back to $70^{\circ} \mathrm{C}$. A rate of $2^{\circ} \mathrm{C} / \mathrm{min}$ was used at a constant frequency of $6.279 \mathrm{rad} \mathrm{s}^{-1}$. All experiments were performed in the linear viscoelastic region using a target strain of $2 \%$.

\section{Results and discussion}

\subsection{Chemical analysis}

The chemical characteristics of the different polysaccharide samples are given in Table 2.

All galactomannan samples exhibit low ash and protein contents, indicating that the purification process of the non-traditional galactomannans (S. japonica and G. triacanthos galactomannans) was efficient, providing polysaccharides with a good quality that is comparable to commercial gums (locust bean gum and guar gum) (Table 2). The ash residue from all the galactomannan samples was too small to measure, demonstrating that their content of monovalent ions (sodium and potassium) is negligible.

The high ash content in the $\kappa$-carrageenan sample reflects the presence of inorganic material that includes ions such as sodium and mostly potassium (Table 2 ). $\mathrm{\kappa}$-Carrageenan is an anionic sulphated heteropolysaccharide strongly influenced by the types of ions found in solution. The potassium ions yield a gel microstructure with rigid superstrands, increasing stability and promoting chain aggregation and the sodium ions give a continuous network of flexible superstrands (Fernandes et al., 1991; Gonçalves, Gomes, Langdom, Viebke, \& Williams, 1996; Nickerson, Paulson, \& Hallett, 2004).

Also xanthan gum is influenced by the type and concentration of ions found in solution and from Table 2 it can be seen that this gum exhibits a substantial amount of sodium ions. Xanthan gum is an extracellular polysaccharide with a semi-rigid chain structure and, in the presence of ions such as sodium or potassium, charge screening causes the side chains to collapse down to the backbone, hence giving the xanthan molecule a rod-like shape and reducing the hydrodynamic volume (Higiro, Herald, Alavi, \& Bean, 2007).

\subsection{Dynamic shear properties}

In order to evaluate the effects of the different galactomannans on the properties of $\kappa$-carrageenan/galactomannan and xanthan/galactomannan mixed gels, dynamic measurements were performed for different mixture ratios of the polysaccharides over a frequency range of $0.1-100 \mathrm{rads}^{-1}$. Fig. 1(a) and (b) shows the values of the storage modulus $\left(G^{\prime}\right)$ of the mixed systems of $\kappa$-carrageenan/S. japonica galactomannan and xanthan/S. japonica galactomannan, respectively. These systems were chosen as examples to demonstrate the typical behavior of the $\kappa$-carrageenan/galactomannan and xanthan gum/galactomannan gels.

The mechanical spectra of the mixed polysaccharide gels are characterized by a modest dependency of the shear storage modulus $\left(G^{\prime}\right)$ over the entire range of frequencies (indeed, $G^{\prime}$ is almost independent of the frequency for $\omega>1 \mathrm{rad} \mathrm{s}^{-1}$ ). Moreover, the rela- 

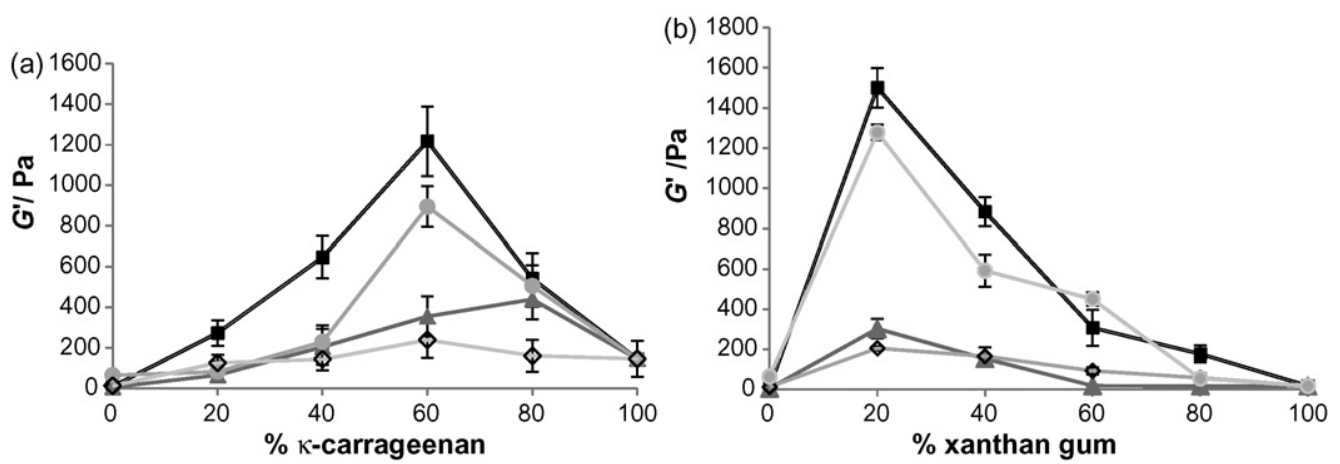

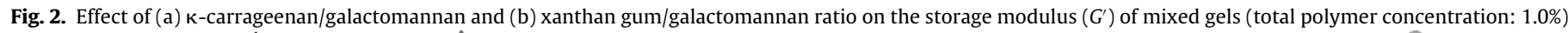

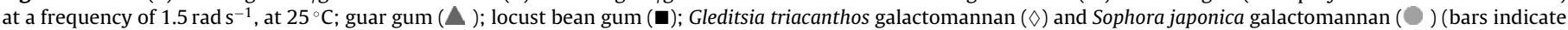
\pm standard deviation limits).

tive order (in terms of the magnitude of $G^{\prime}$ ) of the different systems is preserved over all the frequency range tested, i.e. the differences existing between the systems tested are constant, regardless of the frequency at which the measurements were performed. The $G^{\prime}$ values obtained at $1.5 \mathrm{rad} \mathrm{s}^{-1}$ (frequency taken as representative, given the behavior observed in Fig. 1 and also in other polysaccharide systems-data not shown) from the mechanical spectra at $25^{\circ} \mathrm{C}$ were plotted versus the percentage of $\kappa$-carrageenan and xanthan in the mixtures (Fig. 2a and b, respectively).

(a)

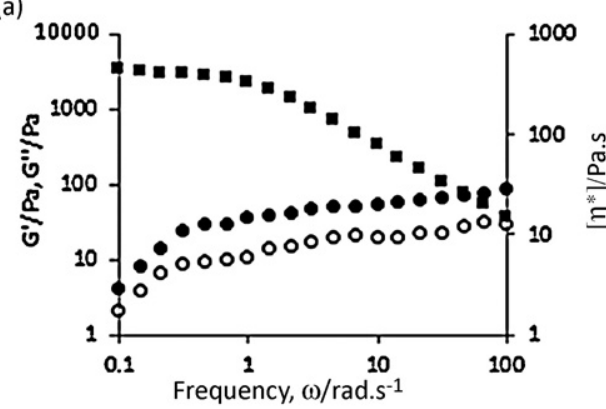

(c)

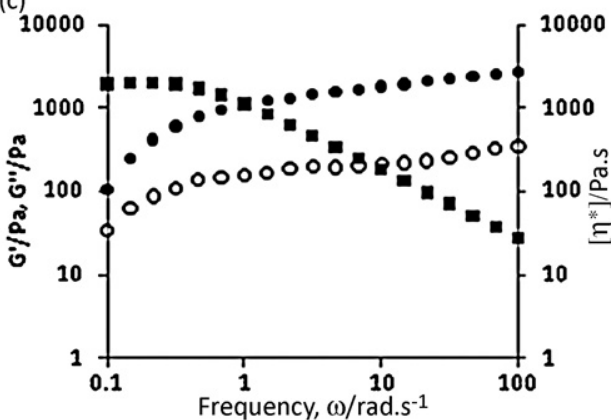

(e)

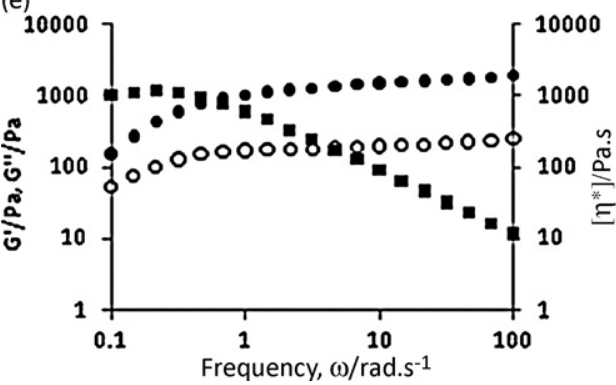

Fig. 2(a) shows the effect of varying $\kappa$-carrageenan concentration on the rheological behavior of $\kappa$-carrageenan/galactomannan blends, where the concentration of $\kappa$-carrageenan is seen to play a crucial role in determining the synergistic interaction of biopolymers. A synergistic maximum of $G^{\prime}$ was obtained at different weight ratios, depending on the galactomannan: 80:20 for guar gum, 60:40 for locust bean gum, 60:40 for G. triacanthos galactomannan and 60:40 for $S$. japonica galactomannan. The results obtained for $\kappa$-carrageenan/guar gum and $\kappa$-carrageenan/locust (b)

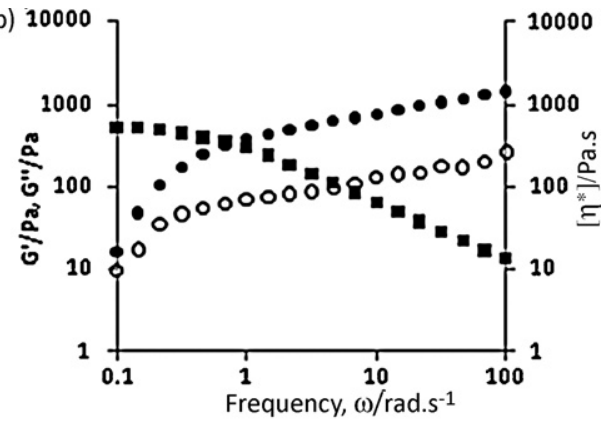

(d)

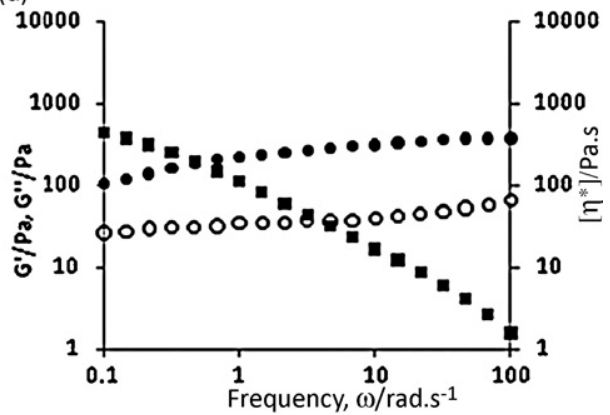

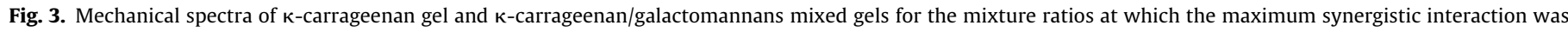

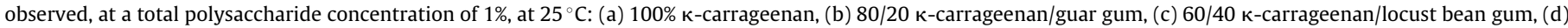

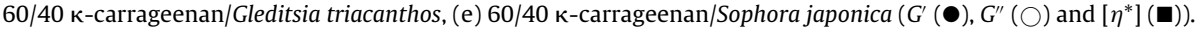



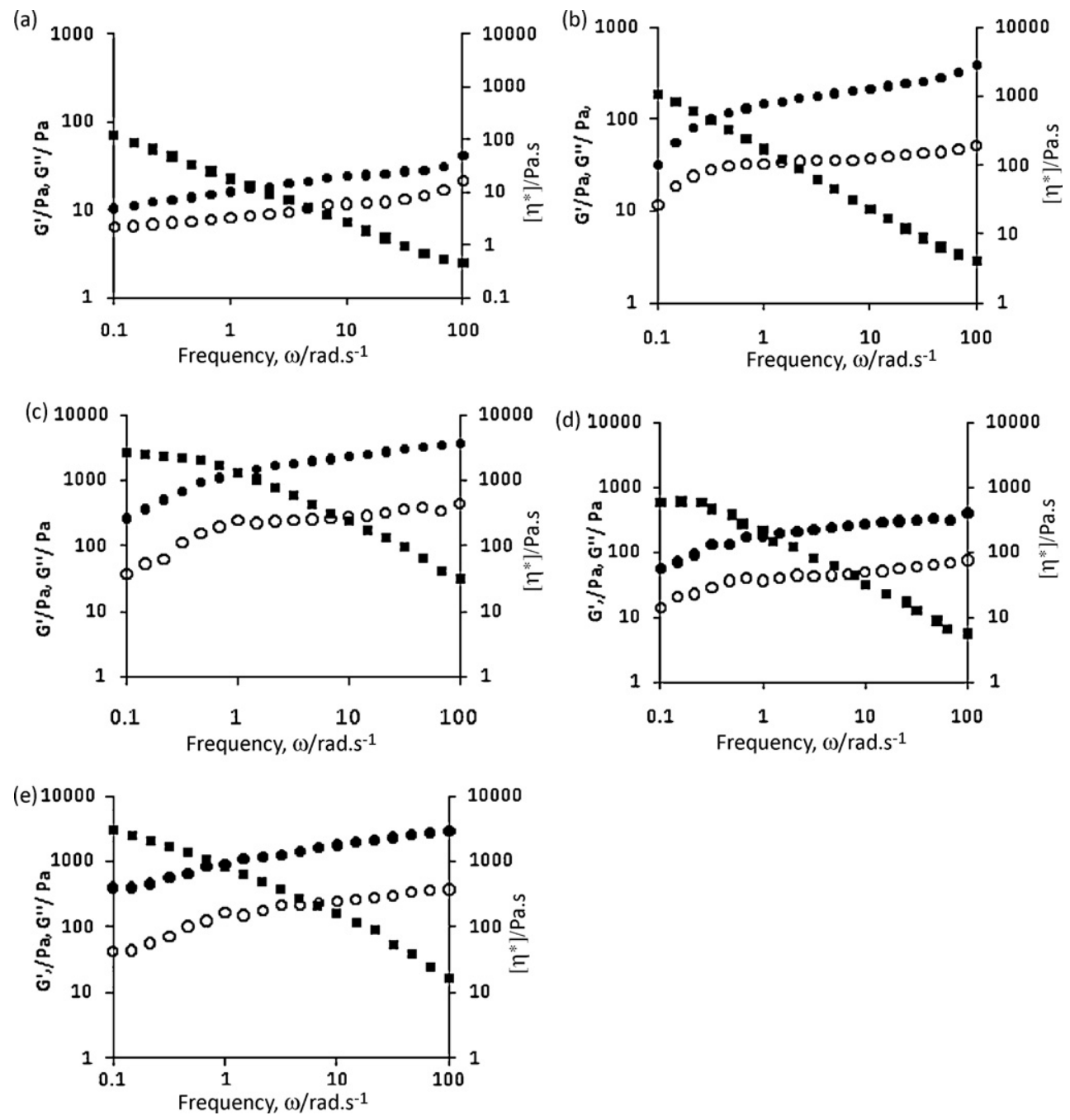

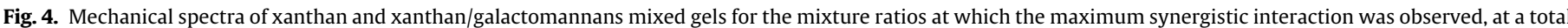

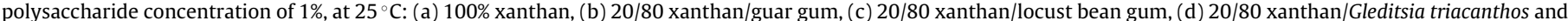
(e) 20/80 xanthan/Sophora japonica $\left(G^{\prime}(\bullet), G^{\prime \prime}(\bigcirc)\right.$ and $\left.\left[\eta^{*}\right](\boldsymbol{\square})\right)$.

bean gum systems are consistent with those obtained by Azero and Andrade (2006) and Hernandez, Dolz, Dolz, Delegido, and Pellicer (2001), respectively. The synergy between $\kappa$-carrageenan/locust bean gum was quite strong while only a slight variation was found for the $\kappa$-carrageenan/guar gum system. Fernandes et al. (1991) reported a higher ratio (80:20) at which maximum locust bean gum and $\mathrm{\kappa}$-carrageenan interactions were observed. This divergence may reflect differences in the purity of the gums, since the locust bean gum used in the present study is a highly refined gum (Table 2) and may reflect the effects of ions concentration in $\kappa$-carrageenan (specially the high potassium content present in the sample used in this work). In fact, the synergistic maximum depends on the salt concentration and can shift from $90 \%$ $\kappa$-carrageenan to $35 \% \mathrm{\kappa}$-carrageenan in $0.1 \mathrm{M} \mathrm{KCl}$ (Dunstan et al., 2001; Stading \& Hermansson, 1993).

For all xanthan/galactomannan systems, the maximum synergy was observed for a ratio of 20:80 (\% w/w). The main variables for xanthan and galactomannan interactions are the molecular xanthan conformation (that changes with the applied temperatures) and the galactomannan structure in solution and, in the case of locust bean gum, the dissolution temperature is also important (Casas \& Garcia-Ochoa, 1999). In the galactomannan structure $\mathrm{M} / \mathrm{G}$ is important but the presence of galactose residues positioned on only one side of the mannan chain also is (Williams \& Phillips,
1995). Ionic strength and $\mathrm{pH}$ are also factors to be considered (Sworn, 2000, chap. 6). The results obtained for xanthan/guar gum system are in agreement with those reported by Sworn (2000, chap. 6 ). For xanthan/locust bean gum mixtures, the maximum interaction has been reported for 50:50 mixtures (Copetti, Grassi, Lapasin, \& Pricl, 1997; Sworn, 2000, chap. 6), however, there are other authors that observed different ratio values. For instance, Casas and Garcia-Ochoa (1999) obtain a maximum for 2:4 in most tested cases, although they also mention that, depending on the dissolution temperature or total gum concentration, this can be displaced to $3: 3$ or $1: 5$ ratios and Wang, Wang, and Sun (2002) showed a maximum gel strength between 0.4:0.6 and 0.6:0.4 xanthan/locust bean gum, depending on salt concentration and hot or cold mixing.

Mechanical spectra obtained for gels of $\kappa$-carrageenan and xanthan alone and for their mixtures with guar gum, locust bean gum, G. triacanthos galactomannan and S. japonica galactomannan are shown in Figs. 3 and 4, respectively, for the mixture ratios at which the maximum synergistic interaction was observed.

As shown in Figs. 3 and 4, the addition of guar gum, locust bean gum, G. triacanthos galactomannan or S. japonica galactomannan leads to the formation of stronger gels, in comparison with $\mathrm{K}$ carrageenan (Fig. 3a) or xanthan alone (Fig. 4a), although this effect is stronger for locust bean gum and S. japonica galactomannan (for higher $\mathrm{M} / \mathrm{G}$ ratios). 
Table 3

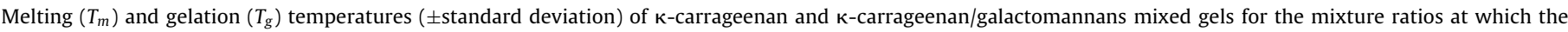
maximum synergistic interaction was observed.

\begin{tabular}{|c|c|c|c|}
\hline Systems & Ratio (\% w/w) & $T_{m} /{ }^{\circ} \mathrm{C}$ & $T_{g} /{ }^{\circ} \mathrm{C}$ \\
\hline к-Carrageenan & 100:0 & $36.20 \pm 0.82^{\mathrm{a}}$ & $27.09 \pm 0.61^{\mathrm{b}}$ \\
\hline к-Carrageenan/Guar gum & $80: 20$ & $35.10 \pm 0.42^{\mathrm{a}}$ & $24.35 \pm 0.64^{b}$ \\
\hline к-Carrageenan/Locust bean gum & $60: 40$ & $45.25 \pm 0.49^{a}$ & $25.10 \pm 0.14^{b}$ \\
\hline к-Carrageenan/Gleditsia triacanthos & $60: 40$ & $39.10 \pm 0.57^{a}$ & $23.20 \pm 0.14^{\mathrm{b}}$ \\
\hline к-Carrageenan/Sophora japonica & $60: 40$ & $42.20 \pm 0.71^{\mathrm{a}}$ & $25.14 \pm 0.14^{\mathrm{b}}$ \\
\hline
\end{tabular}

Probability values were obtained by one-way ANOVA. Different letters in the same line represent statistical different results $(p<0.05)$.

The synergistic effect is illustrated by the rise of $G^{\prime}$ and by the decreased frequency dependence of both moduli due to the presence of galactomannans. This indicates that the addition of a certain amount of galactomannan, regardless of their $\mathrm{M} / \mathrm{G}$ ratios and their fine structures, can enhance the gelling network.

As discussed previously, galactomannans are polysaccharides in which the mannose backbone is partially substituted by single-unit galactose side chains and the degree and pattern of substitution varies between the galactomannans and this strongly influences the extent of interaction with $\mathrm{\kappa}$-carrageenan or xanthan. From Figs. 3 and 4, and as previously pointed out in Fig. 2, it is shown that the magnitude of the synergistic interaction depends on the galactomannan used in the mixture, particularly on their structural differences.

Regarding the $\kappa$-carrageenan systems, and for the mixture ratios at which the maximum synergistic interaction was observed, the highest value of $G^{\prime}$ was obtained for locust bean gum followed by S. japonica galactomannan, guar gum and G. triacanthos galactomannan (Figs. 2a and 3). Dea et al. proposed a mechanism for the interaction between the double-stranded helix of $\kappa$-carrageenan and the unbranched "smooth" segments of the D-mannose backbone of the galactomannan molecules (Dea et al., 1972; Dea \& Morrison, 1975). However, considerable controversy still exists concerning the understanding of the mechanisms involved.

Also for the xanthan/galactomannan interactions there is still much debate about the exact nature of the synergy. However, it is generally accepted that the xanthan gum interacts with the unsubstituted "smooth" regions of the galactomannan molecules (Dea et al., 1977; Morris, 1977). Concerning xanthan/galactomannan blends, locust bean gum and S. japonica galactomannan exhibited stronger interactions with xanthan when compared with guar gum and G. triacanthos galactomannan (Figs. 2b and 4).

It is noteworthy to point out that $\kappa$-carrageenan/locust bean gum and xanthan/locust bean gum systems showed the highest synergistic interactions despite the value of $M / G$ for locust bean gum being of ca. 4, compared to 5.75 for S. japonica galactomannan (Cerqueira et al., 2009). This means that there should be more unsubstituted regions in S. japonica galactomannan than in locust bean gum. However, as pointed out by Dea, Clark, and McCleary (1986), the galactose distribution pattern on the mannan backbone influences the length and frequency of the unsubstituted region.
Thus, the improved synergy of locust bean gum compared to $S$. japonica galactomannan should be attributed to the fine structure of these galactomannans. As expected, the G. triacanthos galactomannan (M/G ratio equal to 2.82, Cerqueira et al., 2009) and guar gum ( $\mathrm{M} / \mathrm{G}$ ratio approximately 2 ) exhibited the lowest interactions with both $\mathrm{\kappa}$-carrageenan and xanthan.

It is also clear that the mechanical spectra obtained for mixtures of locust bean gum with $\kappa$-carrageenan and xanthan (Figs. 3c and 4c) and for blends of S. japonica galactomannan with $\kappa$-carrageenan and xanthan (Figs. 3e and 4e) present the behavior of stronger gels in comparison with the other systems, with higher values of $G^{\prime}$ and $\left[\eta^{*}\right]$ and a lower frequency dependence of both dynamic moduli (particularly in $\omega \geq 1 \mathrm{rad} \mathrm{s}^{-1}$ range).

\subsection{Heating/cooling cycles}

Heating/cooling cycles were performed for $\kappa$-carrageenan and xanthan alone and for mixtures of these polysaccharides with guar gum, locust bean gum, G. triacanthos galactomannan and S. japonica galactomannan, in regime of low-amplitude oscillations at a frequency of $6.28 \mathrm{rad} \mathrm{s}^{-1}$ with an increase in temperature at a rate of $2{ }^{\circ} \mathrm{C} / \mathrm{min}$ and at a total polysaccharide concentration of $1 \%$.

Concerning $\kappa$-carrageenan systems, as the temperature increases and melting occurs, the connectivity between the polysaccharides decrease and the gel network structure is destructed. This is reflected by a progressive predominance of viscous modulus $\left(G^{\prime \prime}\right)$ over the elastic modulus $\left(G^{\prime}\right)$. The inverse behavior was observed during the cooling process. Sol-gel transition was defined by the cross-over of the $G^{\prime}-G^{\prime \prime}$ moduli as described in the case of the physical gels by Cuvier and Launay (1990).

Table 3 show the melting $\left(T_{m}\right)$ and gelation $\left(T_{g}\right)$ temperatures obtained for $\kappa$-carrageenan alone and for $\mathrm{\kappa}$ carrageenan/galactomannans gels correspondent to synergistic maxima.

к-Carrageenan sample exhibited a clear hysteresis $\left(T_{m}>T_{g}\right)$, that is consistent with behavior reported in the literature (Fernandes, Gonçalves, \& Doublier, 1992). These authors obtained a $T_{g}$ between $24^{\circ} \mathrm{C}$ and $25^{\circ} \mathrm{C}$ and a $T_{m}$ of $32^{\circ} \mathrm{C}$. Concerning $\kappa$ carrageenan/galactomannan systems, $T_{m}$ seems to be dependent on the galactomannan present in the blend: the highest values were obtained for locust bean gum and S. japonica galactomannan

Table 4

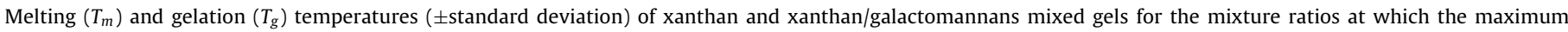
synergistic interaction was observed.

\begin{tabular}{|c|c|c|c|}
\hline Systems & Ratio (\% w/w) & $T_{m} /{ }^{\circ} \mathrm{C}$ & $T_{g} /{ }^{\circ} \mathrm{C}$ \\
\hline Xanthan & 100:0 & $64.43 \pm 5.20^{\mathrm{a}}$ & $64.95 \pm 3.89^{\mathrm{a}}$ \\
\hline Xanthan/Guar gum & $20: 80$ & $32.53 \pm 4.15^{\mathrm{a}}$ & $28.20 \pm 1.57^{b}$ \\
\hline Xanthan/Locust bean gum & $20: 80$ & $53.43 \pm 0.60^{\mathrm{a}}$ & $51.27 \pm 0.40^{\mathrm{b}}$ \\
\hline Xanthan/Gleditsia triacanthos & $20: 80$ & $48.80 \pm 1.25^{\mathrm{a}}$ & $47.23 \pm 0.15^{b}$ \\
\hline Xanthan/Sophora japonica & $20: 80$ & $52.80 \pm 0.53^{\mathrm{a}}$ & $50.93 \pm 0.12^{\mathrm{b}}$ \\
\hline
\end{tabular}

Probability values were obtained by one-way ANOVA. Different letters in the same line represent statistical different results $(p<0.05)$. 
and the lowest values were obtained for G. triacanthos galactomannan followed by guar gum (Table 3). However, in these systems $T_{m}$ and $T_{g}$ also depend on the ionic content and $\kappa$-carrageenan concentration (Fernandes, 1995). The exact temperature for the physical transition may vary slightly, depending on the cooling/heating rate (Rinaudo \& Moroni, 2009). These systems are thermally reversible and a significant $(p<0.05)$ thermal hysteresis was observed between melting and gelation in accordance with previous findings (Andrade, Azero, Luciano, \& Gonçalves, 2000; Fernandes et al., 1991). Furthermore, a higher thermal hysteresis ( $\Delta T=T_{m}-T_{g}$ ) was observed for all $\kappa$-carrageenan/galactomannan mixtures than for $\kappa$-carrageenan alone, as described by Fernandes et al. (1992). These authors reported similar results of $T_{m}$ and $T_{g}$ when $\mathrm{\kappa}$-carrageenan was mixed with locust bean gum $\left(26^{\circ} \mathrm{C}\right.$ and $46^{\circ} \mathrm{C}$, respectively).

Regarding xanthan systems, a progressive change from the behavior of a typical gel to that of a quasi-solution state was observed on increasing of temperature, while cooling process induced gel formation, as also observed for $\kappa$-carrageenan systems. The $T_{m}$ and $T_{g}$ obtained for xanthan alone and for xanthan/galactomannan gels (correspondent to the peak of synergy) can be observed in Table 4 .

Concerning xanthan gum, no thermal hysteresis was detected between melting and gelation. This behavior is a consequence of the fully reversibility of disorder-order transition of xanthan (Agoub, Smith, Giannouli, Richardson, \& Morris, 2007). A slight hysteresis was observed for all the xanthan/galactomannan systems, characterized by a significant $(p<0.05)$ increase of $T_{m}$ over the $T_{g}$ values.

The present results show that the gelation and melting temperatures of these systems is related (although not directly) to the galactomannan $\mathrm{M} / \mathrm{G}$ ratio, among other characteristics such as galactomannans fine structure and molecular weight (Schorsch, Garnier, \& Doublier, 1997).

The value of $T_{m}$ obtained for xanthan/locust bean gum (Table 4) falls nicely in the interval $50-60^{\circ} \mathrm{C}$, which is typical of this system (Fernandes, 1995; Sworn, 2000, chap. 6).

\section{Conclusions}

G. triacanthos galactomannan and S. japonica galactomannan interact with $\kappa$-carrageenan and xanthan to form synergistic gels. The rheological behavior of $\kappa$-carrageenan/galactomannan and xanthan/galactomannan systems suggest a dependency upon both the $M / G$ ratio and the fine structure of the galactomannan chain, since the strongest synergy was obtained for locust bean gum $(\mathrm{M} / \mathrm{G}=4)$ followed by $S$. japonica galactomannan $(\mathrm{M} / \mathrm{G}=5.75)$, guar gum $(\mathrm{M} / \mathrm{G}=2)$ and $\mathrm{G}$. triacanthos galactomannan $(\mathrm{M} / \mathrm{G}=2.81)$.

The galactomannans of $G$. triacanthos and S. japonica represent interesting alternatives to the traditional guar gum and locust bean gum and their mixtures with xanthan or $\kappa$-carrageenan can be used to provide different rheological characteristics to food products.

\section{Acknowledgments}

The author Bourbon, A.I. would like to acknowledge HealthyCream, Project No. 5345 financed by Agência de Inovação (Portugal) and supported by FEDER.

\section{References}

Agoub, A. A., Smith, A. M., Giannouli, P., Richardson, R. K., \& Morris, E. R. (2007) "Melt-in-the-mouth" gels from mixtures of xanthan and konjac glucomannan under acidic conditions: A rheological and calorimetric study of the mechanism of synergistic gelation. Carbohydrate Polymers, 69(4), 713-724.

Andrade, C. T., Azero, E. G., Luciano, L., \& Gonçalves, M. P. (2000). Rheological properties of mixtures of $\mathrm{\kappa}$-carrageenan from Hypnea musciformis and galactomannan from Cassia javanica. International Journal of Biological Macromolecules, 27, 349-353.

Azero, E. G., \& Andrade, C. T. (2006). Characterisation of Prosopis juliflora seed gum and the effect of its addition to $\mathrm{\kappa}$-carrageenan systems. Journal of Brazilian Chemical Society, 17(5), 844-850.

Bourbon, A. I., Pinheiro, A. C., Ribeiro, C., Miranda, C., Maia, J. M., Teixeira, J. A., et al. (2009). Characterization of galactomannans extracted from seeds of Gleditsia triacanthos and Sophora japonica through shear and extensional rheology: Comparison with guar gum and locust bean gum. Food Hydrocolloids, 24(2-3) 184-192.

Bradford, M. M. (1976). A rapid and sensitive method for the quantitation of microgram quantities of protein utilizing the principle of protein-dye binding. Analytical Biochemistry, 72, 248-254.

Casas, J. A., \& Garcia-Ochoa, F. (1999). Viscosity of solutions of Xanthan/locust bean gum mixtures. Journal of the Science of Food and Agriculture, 79, 25-31.

Cerqueira, M. A., Pinheiro, A. C., Souza, B. W. S., Lima, A. M. P., Ribeiro, C. Miranda, C., et al. (2009). Extraction, purification and characterization of galactomannans from non-traditional sources. Carbohydrate Polymers, 75, 408414.

Copetti, G., Grassi, M., Lapasin, R., \& Pricl, S. (1997). Synergistic gelation of xanthan gum with locust bean gum: A rheological investigation. Glycoconjugate Journal, 14, 951-961.

Cuvier, G., \& Launay, B. (1990). Frequency dependence of viscoelastic properties of some physical gels near the gel point. Die Makromolekulare Chemie, Macromolec ular Sympeosia, 44, 23-31.

Dakia, P. A., Blecker, C., Roberta, C., Watheleta, B., \& Paquota, M. (2008). Composition and physicochemical properties of locust bean gum extracted from whole seeds by acid or water dehulling pre-treatment. Food Hydrocolloids, 22, 807818.

Dea, I. C. M., \& Morrison, A. (1975). Chemistry and interactions of seed galactomannans. Advances in Carbohydrate Chemistry and Biochemistry, 32, 241-312.

Dea, I. C. M., Clark, A. H., \& McCleary, B. V. (1986). Effect of molecular fine structure of galactomannans on their interaction properties. The role of unsubstituted sides. Food Hydrocolloids, 1, 129-140.

Dea, I. C. M., McKinnon, A. A., \& Rees, D. A. (1972). Tertiary and quaternary structure in aqueous polysaccharide systems which model cell wall cohesion: Reversible changes in conformation and association of agarose, carrageenan and galactomannan. Journal of Molecular Biology, 68, 153-172.

Dea, I. C. M, Morris, E. R., Rees, D. A., Welsh, E. J., Barnes, H. A., \& Price, J. (1977) Associations of like and unlike polysaccharides: Mechanism and specificity in galactomannans, interacting bacterial polysaccharides, and related systems. Carbohydrate Research, 57, 249-272.

Dunstan, D. E., Chen, Y., Liao, M.-L, Salvatore, R., Boger, D. V., \& Prica, M. (2001). Structure and rheology of the $\kappa$-carrageenan/locust bean gum gels. Food Hydrocolloids, $15,475-484$.

Egorov, A. V., Mestechkina, N. M., \& Shcherbukhin, V. D. (2003). Determination of the primary and fine structures of a galactomannan from the seed of Gleditsia triacanthos $f$. inermis L. Applied Biochemistry and Microbiology, 39, 398402.

Egorov, A. V., Mestechkina, N. M., \& Shcherbukhin, V. D. (2004). Composition and structure of galactomannan from the seed of Gleditsia ferox Desf. Applied Biochemistry and Microbiology, 40, 314-318.

Fernandes, P. B. (1995). Influence of galactomannan on the structure and thermal behaviour of xanthan/galactomannan mixtures. Journal of Food Engineering, 24 269-283.

Fernandes, P. B., Gonçalves, M. P., \& Doublier, J. L. (1991). A rheological characterization of kappa-carrageenan/galactomannan mixed gels: A comparison of locus bean gum samples. Carbohydrate Polymers, 16, 253-274.

Fernandes, P. B., Gonçalves, M. P., \& Doublier, J. L. (1992). Effect of galactomannan addition on the thermal behaviour of $\kappa$-carrageenan gels. Carbohydrate Polymers, $19,261-269$.

Fox, J. E. (1992). In A. Imeson (Ed.), Thickening and gelling agents for food (pp. 153-169). London: Chapman \& Hall.

Gonçalves, M. P., Gomes, C., Langdom, M. J., Viebke, C., \& Williams, P. A. (1996) Studies on $\kappa$-carrageenan/locust bean gum mixtures in the presence of sodium chloride and sodium iodide. Biopolymers, 41(6), 657-671.

Hernandez, M. J., Dolz, J., Dolz, M., Delegido, J., \& Pellicer, J. (2001). Viscous sinergism in carrageenan ( $k$ and $\lambda$ ) and locust bean gum mixtures: Influence of adding sodium carboxymethylcellulose. Food Science and Technology International, 7, 383-391.

Higiro, J., Herald, T. J., Alavi, S., \& Bean, S. (2007). Rheological study of xanthan and locust bean gum interaction in dilute solution: Effect of salt. Food Research International, 40, 435-447.

Miles, M. J., Morris, V. J., \& Carroll, V. (1984). Carob gum-к-carrageenan mixed gels: Mechanical properties and X-ray fiber diffraction studies. Macromolecules, 17(11), 2443-2445

Morris, E. R. (1977). Molecular origin of xanthan solution properties. In P. A. Sandford, \& A. Laskin (Eds.), Extracellular Microbial Polysaccharides (pp. 81-90). Washington DC: ACS Symposium Series 45.

Nickerson, M. T., Paulson, A. T., \& Hallett, F. R. (2004). Dilute solution properties of $\kappa$-carrageenan polysaccharides: Effect of potassium and calcium ions on chain conformation. Carbohydrate Polymers, 58, 25-33.

Ranganna, S. (1977). Handbook of analysis of quality control for fruits and vegetable products (2nd ed.). New Delhi: Tata McGraw-Hill Publishing Co. Ltd. 
Rinaudo, M., \& Moroni, A. (2009). Rheological behavior of binary and ternary mixtures of polysaccharides in aqueous medium. Food Hydrocolloids, 23(7), $1720-1728$.

Schorsch, C., Garnier, C., \& Doublier, J.-L. (1997). Viscoelastic properties of xanthan/galactomannan mixtures: Comparison of guar gum with locust bean gum. Carbohydrate Polymers, 34, 165-175.

Stading, M., \& Hermansson, A.-M. (1993). Rheological behaviour of mixed gels of к-carrageenan-locust bean gum. Carbohydrate Polymers, 22(1), 49-56.
Sworn, G. (2000). In G. O. Phillips, \& P. A. Williams (Eds.), Xanthan gum in handbook of hydrocolloids (pp. 103-116). Cambridge, UK: Woodhead Publishing. Ch.6.

Wang, F., Wang, Y.-J., \& Sun, Z. (2002). Conformational Role of Xanthan in its Interaction with Locust Bean Gum. Journal of Food Science, 67(7), 2609-2614.

Williams, P. A., \& Phillips, G. O. (1995). Interactions in mixed polysaccharide mixtures. In A. M. Stephan (Ed.), Ch 14 in Food polysaccharides and their applications. New York: Marcel Dekker. 